\title{
A COLEÇÃO DIDÁTICA “AS MAIS BELAS HISTÓRIAS” (1954-1976): LIÇÕES SOBRE A FORMAÇÃO DO BRASIL MODERNO*
}

\author{
La colección didáctica "As Mais Belas Histórias" (1954-1976): lecciones sobre la \\ formación del Brasil moderno
}
The textbook collection "As Mais Belas Histórias” (1954-1976): lessons about the formation of modern Brazil

Felismina Dalva Teixeira Silva ${ }^{1}$

Raquel Discini de Campos²

\begin{abstract}
Resumo
Este artigo apresenta a coleção de livros escolares denominada "As Mais Belas Histórias" e a analisa como um artefato cultural. Trata-se de um material para alfabetização distribuído nas escolas primárias de Minas Gerais na segunda metade do século XX, sendo que a primeira edição ocorreu em 1954, e a partir de 1976 houve um declínio na sua comercialização em virtude da mudança da orientação metodológica para o ensino de leitura e escrita no estado. Na coleção, a autora Lucia Casasanta mobiliza inúmeros valores morais em circulação no país desde o século XIX, num momento em que parte da intelectualidade nacional buscava respostas frente a uma sociedade em transformação. Dentre esses valores, se destacam aqueles relativos à modernização, ao nacionalismo e à definição de uma identidade do cidadão ideal a ser construído via educação escolar.
\end{abstract}

PALAVRAS-CHAVE: “As Mais Belas Histórias”. Livro didático. Lúcia Casasanta

\begin{abstract}
This article presents a textbook collection called "As Mais Belas Histórias", and analyzes it as a cultural artifact. It is a material for literacy distributed in the Elementary schools of Minas Gerais in the second half of the $20^{\text {th }}$ century. The first edition was released in 1954 , and since 1976 , there has been a decline in its commercialization due to the change in the methodological orientation for reading and writing teaching in the state. In that collection, the author Lucia Casasanta mobilizes innumerable moral values in current circulation in the country since the $19^{\text {th }}$ century, at a time when part of the national intellectuality was looking forward responses facing a changing society. Among these values, the most important are those related to modernization, nationalism and to the definition of an ideal citizen's identity to be built through school education.
\end{abstract}

KEYWORDS: “As Mais Belas Histórias”. Textbook. Lúcia Casasanta

\section{Resumen}

Este estudio presenta la colección de libros escolares denominada "As Mais Belas Histórias" y la analiza como un artefacto cultural. Se trata de un material para la alfabetización, distribuido en las escuelas primarias de Minas Gerais en meados del siglo XX. A primera edición es de 1954. A

\footnotetext{
*Este artigo é parte da tese intitulada “A coleção didática 'As Mais Belas Histórias' (1954-1976): modernização, nacionalismo e identidade brasileira na obra de Lúcia Casasanta defendida no Programa de Pós Graduação em Educação da Universidade Federal de Uberlândia em 2017. Sob a orientação da professora Dr ${ }^{a}$ Raquel Discini de Campos.

${ }^{1}$ Doutora em Educação, professora da Universidade Federal dos Vales do Jequitinhonha e Mucuri /UFVJM.

${ }^{2}$ Doutora em Educação, professora da Universidade Federal de Uberlândia/UFU.
} 
partir de 1976, se produjo una disminución de la publicación en virtud de la modificación de la orientación metodológica para el curso de lectura y escritura en el estado. En la colección, la autora Lucia Casasanta moviliza los numerosos valores en circulación en el país en un momento en que parte de la intelectualidad buscaba las respuestas frente a una sociedad en transformación. Entre ellos se destacan los de la modernización, el nacionalismo y la definición de una identidad del ciudadano ideal a ser construido a través de la educación escolar.

PALABRAS CLAVE: “As Mais Belas Histórias”. Libro de texto. Lúcia Casasanta

\section{INTRODUÇÃO}

\section{A coleção}

As reflexões de historiadores que passaram a tomar o livro como objeto cultural desvelaram, por intermédio de seu escrutínio, diferentes práticas e representações presentes tanto em suas páginas quanto em seu uso cotidiano. Neste artigo, seguindo a trilha aberta por Chartier (1998); Bittencourt (2004); Nunes; Carvalho (2005) e Darnton (2010), dentre outros autores, busca-se analisar a coleção de livros escolares da autora mineira Lúcia Casasanta, denominada "As Mais Belas Histórias", concebendo-a como um artefato cultural.

Tais livros foram utilizados nas escolas de Minas Gerais a partir de meados do século XX e distribuídos pelo governo visando o ensino da leitura. As histórias neles presentes, editadas desde o ano de 1954, contadas e recontadas por gerações a partir de então, permaneceram por décadas sendo utilizadas nas escolas das regiões rurais e urbanas do Estado. Foram preservadas, principalmente, na memória daqueles que foram alfabetizadas por meio delas.

Este estudo tem como pressuposto a ideia de que a produção de um livro, que é um bem cultural, está necessariamente inscrita num universo regido por interesses econômicos, mas, também, por ideais, valores, projeções de passado e de futuro daqueles envolvidos tanto na sua produção quanto no seu consumo. A respeito da complexidade deste tipo de objeto, Bittencourt (2004) afirma que:

\footnotetext{
Apesar de ser um objeto bastante familiar e de fácil identificação, é praticamente impossível defini-lo. Pode-se constatar que o livro didático assume ou pode assumir funções diferentes, dependendo das condições, do lugar e do momento em que é produzido e utilizado nas diferentes situações escolares. Por ser um objeto de "múltiplas facetas", o livro didático é pesquisado enquanto produto cultural; como mercadoria ligada ao mundo editorial e dentro da lógica de mercado capitalista; como suporte de conhecimentos e de métodos de ensino das diversas disciplinas e matérias escolares; e, ainda, como veículo de valores, ideológicos ou culturais (BITTENCOURT, p. 1, 2004).
}

Em 1954, "As Mais Belas Histórias" foram lançadas no mercado. O conjunto é formado por um pré-livro, cinco livros de leitura, cadernos de atividades, um conjunto de cartazes para alfabetização e livros do mestre. A coleção foi escrita de acordo com as modernas teorias sobre alfabetização em circulação no período; contou com o cuidado técnico e o suporte da Editora do Brasil; e foi amparada administrativamente pela rede de relações da autora. Conforme informa Hallewell (1985) a respeito da editora do Brasil, a casa foi fundada em 1943 por profissionais que haviam trabalhado na produção de livros 
didáticos da Companhia Editora Nacional, se tornando uma importante editora de livros didáticos e infantis ao longo do século XX.

A coleção estava em consonância com as propostas pedagógicas então em voga, com a seriação do ensino que então se consolidava e também com as políticas públicas educacionais mineiras em curso. Por isso, recebeu formalmente o aval do governo para ser consumida pelo público escolar. Dentro dessa perspectiva, podemos afirmar que a coleção foi pensada em sua função pedagógica, mas teve sua dimensão escolar ampliada em função de uma política administrativa (CHOPPIN, 2009; BATISTA; GALVÃO, 2009).

Entre a intenção de uso proposta pela autora/editora e o uso efetivo nas escolas, encontra-se a entrada no país de recursos financeiros oriundos do acordo entre o Ministério da Educação e Cultura e os Estados Unidos, o MEC/USAID, especialmente o Programa de Assistência Brasil/Estados Unidos ao Ensino Elementar (PABAEE). Essa parceria assegurou ao governo recursos suficientes para a edição e distribuição de milhares de exemplares por todo o estado ${ }^{3}$. Um elemento não desprezível na análise da abrangência da obra é o fato de se constituir numa série graduada de seis livros, o que revela a dimensão do número de livros em circulação (PAIVA; PAIXÃO, 1995, MACIEL, 2001).

Independentemente da qualidade inegável d'As Mais Belas Histórias, responsiva às demandas educacionais de determinados grupos sociais daquele tempo e espaço, é evidente que o fortalecimento da Editora do Brasil no mercado mineiro, as parcerias MEC/USAID, bem como a rede de relações sociais da autora foram condições para o sucesso editorial dos livros.

É possível inferir, ainda, que a proximidade de Lúcia Casasanta junto a determinados segmentos intelectuais e políticos, fortaleceu a inclusão da coleção na lista dos livros editados pelo órgão do governo, bem como sua aprovação pela Comissão Nacional do Livro Didático - CNLD. Abgar Renault e Arduíno Bolívar, ambos mineiros e intelectuais atuantes na subcomissão de Literatura e Línguas da CNLD (CPDOC, 1967), têm textos na Coleção na condição de autor (Bolívar) e tradutor (Renault). Mario Casasanta, por sua vez, além de marido de Lucia, era um influente intelectual que se encontrava à frente da execução de uma reforma educacional em Minas Gerais na década de 1950. Era o responsável pela implementação das ações do PABAEE no estado (CUNHA, 1981; PAIVA; PAIXÃO, 1995).

Destaque-se que o modelo graduado de organização escolar atendia à necessidade de escolarização das massas. Conforme Souza (2008, p. 41): uma "decisão racional, adequada à expansão do ensino primário nos núcleos urbanos". Nesse processo de expansão, a utilização do livro foi um dos mais importantes recursos didáticos empregados para a concretização do próprio modelo escolar que então se constituía. Além disso, o livro se tornou parte importante da produção editorial do país. De acordo com Moreira e Podrigues (2017) "considerando as condições de produção do livro como impresso, ele se apresenta como um objeto cultural e mercadológico" (MOREIRA; PODRIGUES, 2017, p.62). Ao realizar a tiragem do primeiro livro, por exemplo, havia garantia de que os exemplares subsequentes seriam impressos, uma vez que os leitores/consumidores estariam supostamente assegurados.

As análises a respeito desse importante artefato cultural revelam que a graduação

\footnotetext{
${ }^{3}$ Nos arquivos do Fundo Arquivístico Lúcia Casasanta, localizados na Biblioteca Alaíde Lisboa da Faculdade de Educação da Universidade Federal de Minas Gerais, foram localizadas informações sobre as tiragens da coleção no período de 1972 a 1976, que totalizaram 1.566.792 exemplares publicados.
} 
do ensino não era decorrente de uma questão exclusivamente pedagógica, de caráter curricular, mas entrelaçada às questões econômicas que envolviam a racionalização dos custos da educação e, também, os lucros das editoras. Era interessante para o mercado que permanecesse a lógica da seriação. As necessidades demandadas pelo segmento editorial, por sua vez, fortaleceram a cultura de um ensino fragmentado em grades curriculares a partir do uso dos livros didáticos.

Destaque-se que foram realizadas ações de marketing da Editora do Brasil para a divulgação da coleção. Em 1955, antes da distribuição, a Editora do Brasil em Minas Gerais encaminhou uma carta às educadoras do Estado, contendo uma lista de livros e solicitava que fossem apreciados. ${ }^{4}$ As características do documento indicavam uma padronização, uma espécie de mala direta, permitindo supor que sua divulgação tenha sido maciça. Foi incluído um adendo ao material de divulgação afirmando que foram "preparados rigorosamente de acordo com os programas vigentes no ensino primário do estado de Minas Gerais, aprovado pela Secretaria de Educação" (AE/2014).

A presença desse material nos espaços escolares exerceu uma importante função: estabeleceu uma demarcação clara sobre qual tipo de livro seria adequado para constar nas salas de aula a partir de então (GATTI JÚNIOR, 2005).

Observamos que pelas solicitações de materiais das escolas, a partir de junho de 1960, os antigos pedidos de livros de catecismo foram substituídos pelos da coleção "As Mais Belas Histórias", totalizando quase 800 exemplares entre livros do mestre e pré-livro (AE, 2014). No entanto, os dados encontrados nos arquivos das escolas visitadas fornecem evidências de que até 1959 os livros religiosos ainda eram utilizados como livros escolares, num processo de longa duração. Um pedido de material didático de uma delas era constituído por uma lista de livros de catecismo (AE, 2014). O fato de serem editados pela José Olympio, uma das principais editoras do período, no auge da defesa da laicização do ensino, demonstra quão tênue continuava a linha entre livro escolar e livro religioso.

Apesar da força da coleção em relação aos antigos manuais de catecismo até então adotados, nota-se que não houve uma ruptura radical em relação ao conteúdo religioso no interior da própria obra - pelo contrário. A cultura católica é constitutiva d'As Mais Belas Histórias, conforme podemos observar nas imagens a seguir.

Na figura 1, Nossa Senhora Aparecida, padroeira do Brasil, esparge suas bênçãos por todo o país. Abençoa e protege o território com seu manto sagrado. Símbolo pátrio (o mapa) e signo religioso (a Virgem) compõem a ilustração. Na figura 2, por sua vez, temos o menino ajoelhado diante de um altar doméstico cuja centralidade é ocupada tanto pela Virgem quanto pela Bandeira Nacional. Novamente, símbolos religioso e pátrio compõem a centralidade da cena. A figura 2, no entanto, remete também à intimidade e ao aconchego do lar. O menino está pronto para dormir, de pijama e chinelos. E reza, antes do merecido repouso da noite.

\footnotetext{
4 Os livros eram "Vamos conhecer Minas Gerais", "Lili e Paulinho estudam ciências Naturais" das autoras Leonilda Montandon e Elza de Moura. Foram localizados em arquivos escolares localizados no Vale do Jequitinhonha, MG. A sigla AE se refere a tais arquivos.
} 
Figura 1- O Brasil sob a proteção de Nossa Senhora

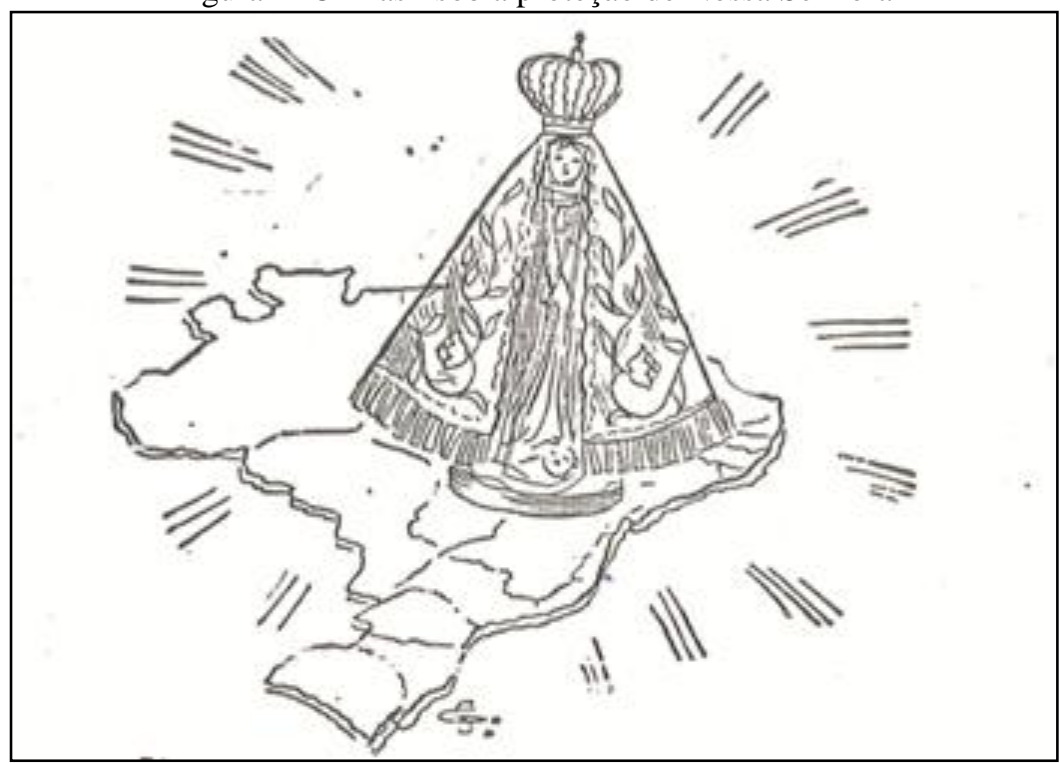

Fonte: CASASANTA (segundo livro, 1969, p.156)

Figura 2 - A protetora do lar

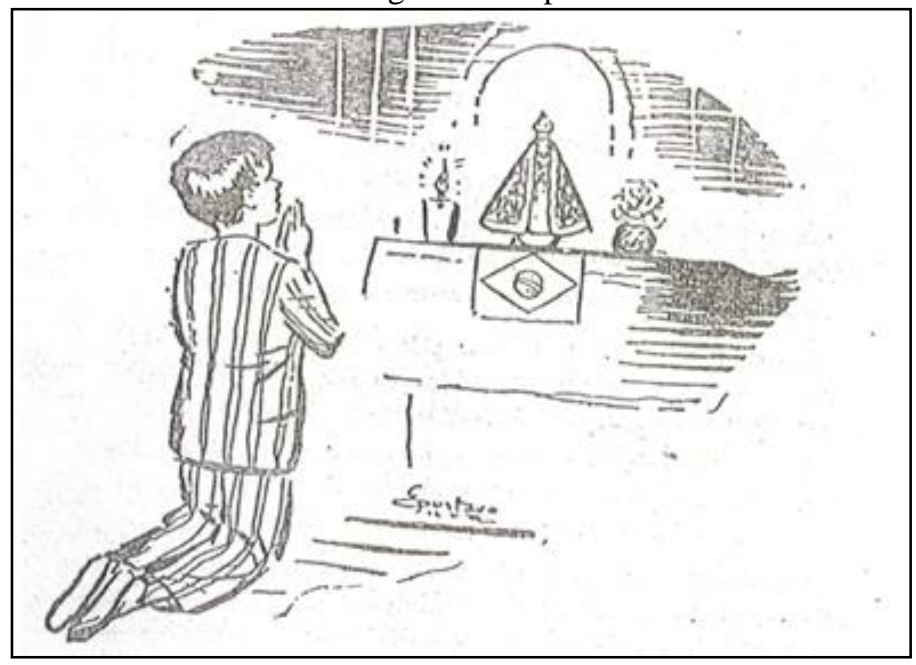

Fonte: CASASANTA (quarto livro, 1969, p.29)

O hibridismo entre cultura laica e católica presente na obra de Lúcia Casasanta, aponta para uma tendência de relativização nas análises sobre a disputa histórica ocorrida entre católicos e os autointitulados pioneiros da educação no país. Pesquisas indicam não ter havido apenas oposições entre grupos antagônicos, mas, também, composições possíveis e aproximações (FREITAS; BICCAS, 2009; CURY, 2010). A figura de Nossa Senhora Aparecida, a mater amantíssima e piedosa, atravessa as páginas d'As Mais Belas Histórias ora protegendo o país e todo o povo brasileiro, ora resguardando crianças indefesas na intimidade de seus lares (Figura 2). 


\section{A autora}

Qual foi a trajetória da autora Lúcia Casasanta? Qual a superfície social dessa professora, que possibilitou a escrita e a publicação, durante décadas, de uma série graduada de livros? Em que ponto sua história se encontra com a história da educação em Minas Gerais? Aspectos biográficos deste indivíduo são compreendidos a partir do pressuposto de que Casasanta foi, ao mesmo tempo, um sujeito singular e social, que construiu a si própria e a sua época num mesmo movimento em que também foi construído por ela, conforme ensinou Jacques Le Goff (2010) ao escrever a biografia de S.Luis.

A vida e a obra de Casasanta (1908-1989) foram tema da pesquisa pioneira de Maciel (2001). Ela buscou compreender a contribuição do trabalho da autora no contexto da história da alfabetização em Minas Gerais, concluindo que a professora teve um papel essencial na defesa e na propagação do método global de contos. A coleção serviu como instrumento para essa divulgação. Podemos pensar em Lúcia Casasanta também como uma intelectual da educação na acepção de Sirinelli (1996), já que ela exerceu a função de mediadora cultural ao realizar a disseminação de ideias sobre a formação do povo brasileiro presente nas histórias do material didático.

É importante ressaltar que dentre as unidades federadas, Minas Gerais apresentou uma força significativa nas questões ligadas às políticas da educação a partir dos anos finais da década de 1920. Desde a criação do Ministério da Educação e Saúde, políticos e intelectuais desta região tiveram um papel importante no órgão ${ }^{5}$.

Em 1927, Francisco Campos, Secretário do Interior do governo Antônio Carlos, iniciou uma série de reformas na educação no estado. Campos considerava que a maior causa do fracasso do ensino era o professorado (MACIEL, 2001; SOUZA, 1984). Nessa lógica, defendia a necessidade de investir na aprendizagem de metodologias que garantissem a melhoria do ensino. Por isso, o secretário enviou um grupo de professoras para se especializarem no Teacher's College, instituição ligada à Universidade de Colúmbia, na cidade de Nova York, nos Estados Unidos. ${ }^{6}$

Essa instituição era referência nas pesquisas em educação já nas décadas de 1920 e 1930, e tinha em seu quadro teóricos do porte de John Dewey (1859-1952). Entre os professores do curso de especialização, encontrava-se um dos colaboradores de Dewey, William Kilpatrick, que era entusiasta da teoria da pedagogia ativa e foi o principal responsável pelo desenvolvimento de trabalhos que buscavam aplicar as ideias desse educador na prática (MACIEL, 2001; PALMER, 2005).

Lúcia Schmidt Monteiro de Castro $^{7}$ foi escolhida para a viagem de estudos e se especializou em Metodologia da Linguagem. O curso durou de 1927 a 1929, e, quando regressou ao Brasil, assumiu a cadeira dessa matéria na Escola de Aperfeiçoamento. A escola foi criada em 1929, em Belo Horizonte, para que os professores do Estado se

\footnotetext{
${ }^{5}$ Muitos políticos que ocuparam o cargo no Ministério da Educação eram mineiros ou fixaram residência em Belo Horizonte. Francisco Campos, (1930-1932); Gustavo Capanema (1934-1945); Edgar Santos (07-1954 a 09-1954); Cândido Mota Filho (1954-1955); Abgar Renault (1955-1956); Clóvis Salgado da Gama, (1956). A partir de 1957, políticos de outros estados ocuparam o cargo, no período em que Juscelino Kubitschek, outro mineiro, assumiu a presidência da República (1956-1961).

${ }^{6}$ O grupo era formado, por Lúcia Schmidt Monteiro de Castro, Alda Loddi, Benedicta Ribeiro Valadares, Amélia de Castro Monteiro e Ignácia Guimarães.

${ }^{7}$ Nome de solteira da professora Lúcia. Em 1933, ela se casou com Mário Casasanta, nome utilizado para assinar suas obras (MACIEL, 2001).
} 
aperfeiçoassem em novas metodologias, conforme aspiração de Francisco Campos (MACIEL, 2001; SOUZA, 1984).

No exercício da docência na disciplina Metodologia da Linguagem, a professora estimulava as alunas a elaborarem materiais didáticos de acordo com a proposta do método global para o ensino da leitura. Em 1954, ela própria publicou seu material em forma de coleção, denominado "As Mais Belas Histórias".

Elas foram construídas e postas em circulação em Minas Gerais, que era um estado considerado por muitos como uma referência nacional no que dizia respeito à temática educacional, uma espécie de "celeiro pedagógico" em razão das reformas realizadas por Campos/Mário Casasanta na década de 1930 (PAIVA; PAIXÃO, 1995; SOUZA, 1984). Nos anos de 1950, Abgar Renault ${ }^{8}$, no Ministério da Educação (1955-1956), e Mário Casasanta, na direção do Instituto de Educação em Minas Gerais, buscavam renovar em Belo Horizonte o clima de capital pedagógica do Brasil, os tais "tempos áureos" dos anos de 1930. A reforma da década de 1950 trazia a característica de ser executada pelo próprio Casasanta em razão dos cargos importantes que ocupava (CUNHA, 1981; PAIVA; PAIXÃO, 1995).

Uma pequena amostragem desse momento está presente nos dados do Anuário Estatístico (1954/1955) e nos dão indícios da importância do assunto Educação no período. No item cultura, em 1954, foram realizados, em Minas Gerais, sete congressos sobre educação e ensino, e 12 conferências sobre Psicologia e Pedagogia (IBGE, 1955). A publicação, naquele tempo e espaço, pode ser considerada um dos fatores significativos dessa nova configuração do ideário escolanovista em Minas Gerais, quase 25 anos após a reforma Francisco Campos. A circulação do material teve seu início no governo de Vargas/Café Filho, e fortaleceu-se ao longo do governo de Juscelino Kubitschek sobrevivendo, portanto, a importantes mudanças políticas.

\section{Algumas lições}

A coleção é um artefato cultural onde observamos inúmeras representações em circulação no país em determinado tempo e espaço. Situada cronologicamente a partir do ano de 1954, e pedagogicamente ancorada numa proposta de educação dos anos de 1920 e 1930, ela atualizou um conjunto de teorias que circulou no Brasil desde o final do século XIX. Foram apresentadas as lições de modernização, nacionalismo e identidade que deveriam ser aprendidas cotidianamente pelos alunos. Elas tinham o propósito de educar o futuro cidadão preparando-o para a experiência de construção de um país que necessitava se modernizar, conforme criam muitos dos grupos sociais do período.

Por isso, valores como o progresso, o trabalho, o culto aos heróis do passado, as práticas da religiosidade com forte influência do catolicismo e a glorificação dos símbolos nacionais foram reatualizados. De fato, a presença desses ensinamentos nas páginas d'As Mais Belas Histórias era alicerce para a construção dos novos rumos que pareciam, finalmente, despontar na aurora da história pátria. Buscava-se pavimentar, seguramente, o caminho do povo brasileiro rumo a um tempo diferente daquele vivido até então. Nos

\footnotetext{
${ }^{8}$ Abgar Renault, antes de assumir o Ministério da Educação, foi membro avaliador de livro didático da CNLD. O professor mineiro Arduíno Bolívar também foi membro avaliador dessa comissão. (CPDOC, 1967).
} 
textos, procurava-se fortalecer ao máximo o sentimento de pertencimento ao país, bem como a identidade de um brasileiro que se orgulhasse da sua terra, de maneira a estimular uma espécie de salto na história nacional, conforme podemos observar no texto abaixo:

\footnotetext{
Orgulho-me de ser brasileiro

O meu país é dos maiores, dos mais ricos e dos mais belos'.

Tem rios numerosos, grandes alguns, como o Amazonas e o São Francisco; outros, menores, que irrigam seus campos; outros encachoeirados que vão dar a energia elétrica, sem a qual as fábricas não trabalham e não pode haver progresso'.

Pela riqueza e pela extensão do solo da minha Pátria, orgulho-me de ser brasileiro'.

'E o homem, o brasileiro? Não é menor. O povo brasileiro é um povo; é corajoso, forte, destemido, e se não soubesse ele amar sua pátria, ah! Já não poderia dizer que meu país era grande'(CASASANTA, quarto livro, 1969, p. 3134).
}

No que diz respeito à temática da urbanização, a Coleção apresenta lições que procuraram educar para um modus vivendi citadino. A construção de novas cidades, bem como o reordenamento das antigas eram elementos indicadores de progresso do país. A temática ganhou centralidade no livro de leitura intermediária, com a sugestão dada por vários animais para construir um lugar onde morar, migrando definitivamente da floresta, considerada arcaica, para a cidade, espaço da alegria e da ordem racionalizada.

Conforme a narrativa de Casasanta, logo houve entre os animais um movimento para propiciar ao local escolhido um conjunto de ações necessárias para dotá-lo de infraestrutura e serviços urbanos. Os textos, dirigidos a um público que estava iniciando o desenvolvimento da leitura, carregavam lições sobre a organização das cidades nos seus mais diversos aspectos. Discutia-se desde a importância do traçado das ruas, da edificação de determinados tipos de casas, do conforto dos lares burgueses a serem construídos e muito bem mobiliados, dos hábitos de higiene e asseio praticados pelos seus habitantes.

As histórias relativas à construção da "cidade dos bichos" denotam iniciativas altamente técnicas na sua edificação, tais quais eram aplicadas pelos engenheiros, médicos e urbanistas dos séculos XIX e XX em alguns municípios e que incidiram fortemente sobre os espaços urbanos do período (HERSCHMAN; PEREIRA, 1994). Não por acaso, Belo Horizonte, cidade onde Lúcia morava, é um desses exemplos de urbe construída para ser uma espécie de "cartão-postal" da suposta "evolução" e "progresso" mineiros (COSTA; SCHWARCZ, 2000; FARIA FILHO, 2000).

A ilustração a seguir (Figura 3) é significativa. Temos um espaço limpo, organizado, simétrico, harmônico. A urbe é apresentada com todas as aparentes comodidades capitalistas. Possui calçamento, ruas com paralelepípedo, iluminação pública e casas de alvenaria, com telhados em duas águas. Algumas têm um pequeno jardim. Temos um lobinho muito entusiasmado em primeiro plano circulando pela larga avenida outro sinal de racionalização - mochila com livros e cadernos nas costas. É significativo também o destaque dado à escola, espaço para onde todos os bichos, com seus respectivos materiais escolares, se dirigem num misto de entusiasmo e alegria, verdadeiramente arrebatados.

Destaque-se que o olhar do leitor é dirigido à escola, que ocupa o "ponto de fuga" da ilustração. $O$ texto que arremata a cena ensina que "o que torna um povo independente 
não é apenas um governo soberano, mas é também a cultura, que lhe liberta o espírito, e a exploração de seus recursos, que o livra da exploração de outros povos" (CASASANTA, quarto livro, 1969, p.159).

Figura 3 - A caminho da escola

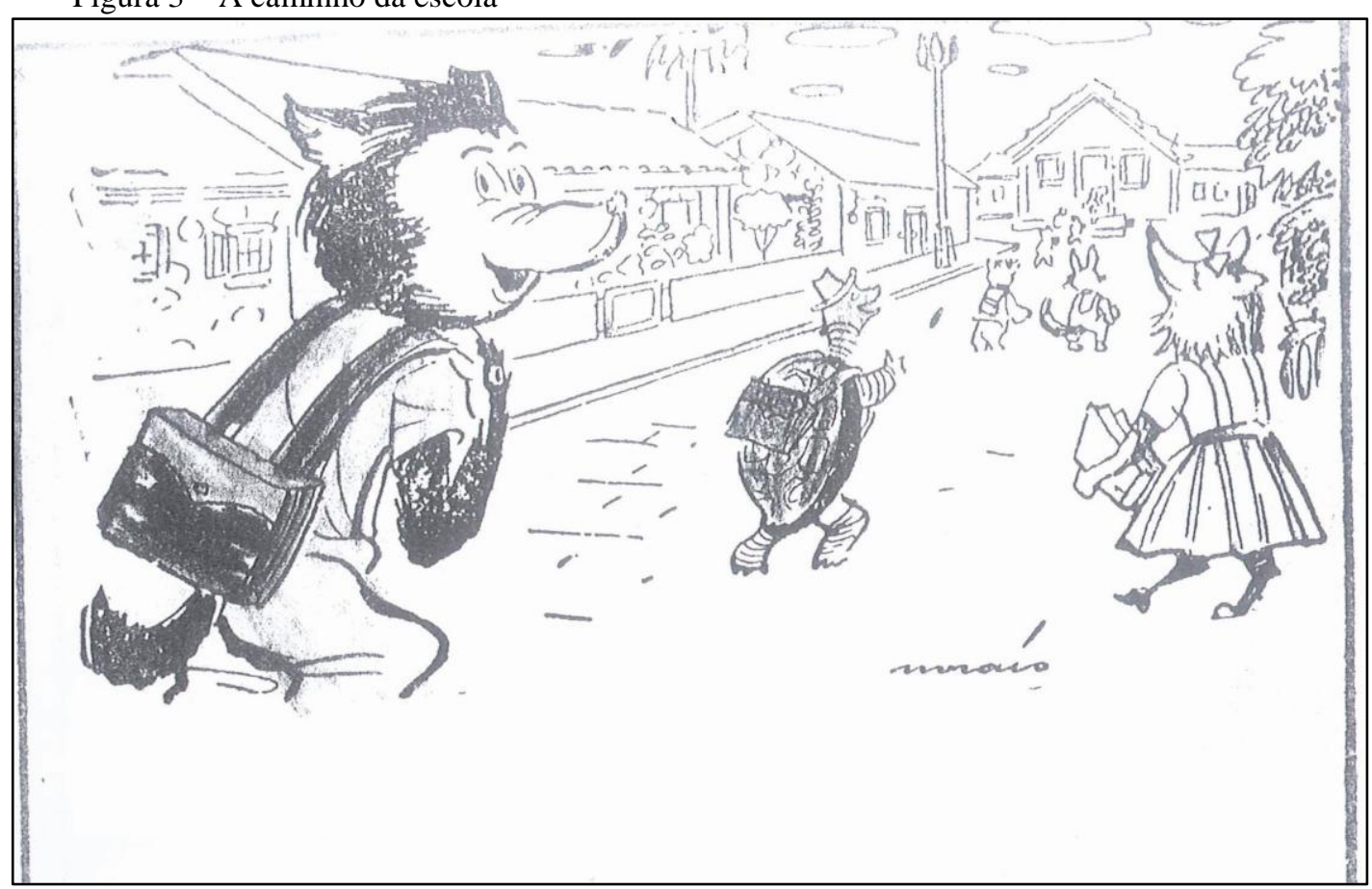

Fonte: CASASANTA (intermediária, 1969, p.25).

O diagnóstico de uma independência inconclusa do país estava atrelado à urgência da modernização do Brasil, nos campos e na cidade:

E sabem o que mais? O povo brasileiro ainda não está inteiramente independente. Só pelo trabalho, só pelo desenvolvimento da indústria, da agricultura, do comércio, só pela valorização do homem brasileiro, é que nosso povo acabará de fazer a independência do Brasil (CASASANTA, terceiro livro, 1969, p. 57).

A Coleção naturalizava, ainda, o consumo de objetos e utensílios típicos das cidades: pia, torneira, fogão elétrico, quadros e cortinas são encontrados na casa de Pedrico, o famoso porquinho das histórias de Casasanta. A posse de tais bens era entendida como sinal de força econômica, mas também de comprometimento pessoal.

A temática do consumo se desdobrava para a diferenciação entre o trabalho intelectual e manual. $\mathrm{O}$ primeiro era atrelado à figura de Pedrico, o personagem escolarizado: leitor voraz, como observado na biblioteca de sua casa (Figura 4). Sua imagem é um contraponto ao trabalho manual ou à preguiça dos seus dois irmãos, Palhaço e Palito. Estes dois, em razão de suas escolhas, são apresentados como menos inteligentes e indolentes - e, justamente por isso, sempre tem que recorrer a Pedrico, ao irmão exemplar, em caso de necessidade. Na ilustração abaixo, observamos um enfadado Palhaço lavando os pratos na pia, enquanto Palito caminha sorridente pela casa, como sempre burlando as regras. Pedrico, invariavelmente aplicado, compenetrado, está de óculos, lendo 
um "livrão grosso" conforme enunciado, apartado dos demais em sua biblioteca.

Figura 4 - A casa de Pedrico

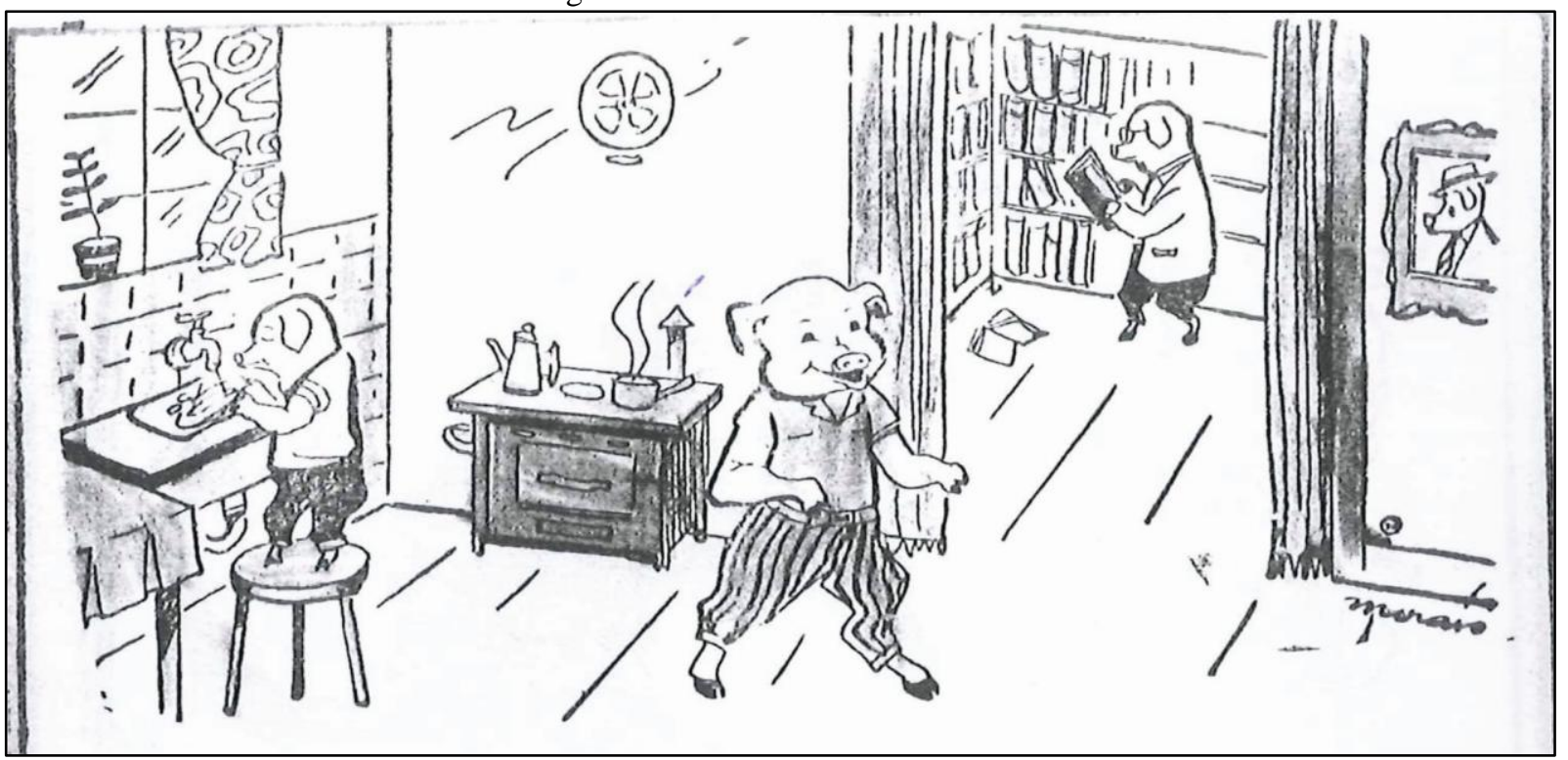

Fonte: CASASANTA (intermediária, 1969, p.20).

Por intermédio da leitura d'As Mais Belas Histórias a criança, ainda no início da alfabetização, era educada por meio dos textos e das ilustrações para a valorização do trabalho, resultante do conhecimento científico. O livro, por sua vez, representa conhecimento adquirido e está à mostra nas prateleiras, espalhado sobre as mesas e nas mãos do porquinho, sugerindo acesso fácil - desde que se dominasse corretamente os códigos de leitura, o que só seria alcançado com a frequência à escola.

Se, por um lado, observamos a contínua exaltação do progresso e do modo de vida urbano, por outro lado observamos forte presença de signos relativos ao mundo rural nas histórias da coleção. A fazenda, o sítio, a roça, ou as rocinhas, dependendo do registro e do tamanho da propriedade rural, são apresentados de maneira saudosista, idealizada, fugidia. Essa tensão perpassa parte das histórias dos livros. Assim observamos no poema "De volta" que busca sintetizar a emoção daquele que retorna ao seu torrão natal. (CASASANTA, terceiro livro, 1969, p. 142 - 143). O retorno é romantizado e tudo parece estar no lugar quando se olha para trás, quando o migrante volta à terra que deixou. Neste chão de terra tão familiar, onde inexoravelmente imperam o conforto e o reconhecimento, o cavaleiro pode, inclusive, dar "rédea ao cavalo", visto que o animal provavelmente reconhece o caminho de volta.

De volta

Minha terra... Ai, com que abalo,

Com que sincera emoção,

$\mathrm{Eu}$, dando rédea ao cavalo,

Margeio este fundo valo

- Caminho do meu torrão.

$[\ldots]$

Tudo no ar, festa e brilho!

E é com a alma a vibrar,

Que eu corto as roças de milho

Por este sinuoso trilho 
Que à minha terra vai dar. (SETÚBAL ${ }^{9}$ apud CASASANTA, terceiro livro, 1969, p. 142).

O mesmo tom saudosista está presente no poema Juca Mulato. A perda de uma espécie de pertencimento ao mundo natural - que é recorrente nas histórias - evidencia a compreensão de um Brasil que se transformava inexoravelmente. Enquanto nas representações sobre cidade o movimento era o de exaltação do progresso e dos comportamentos tidos como civilizados, acentuavam-se nas narrativas sobre o mundo rural, a beleza da natureza, o conforto da vida simples no campo, bem como os dilemas do caboclo migrante, como é o caso de Juca Mulato. No famoso poema do modernista Menotti del Picchia, compilado por Casasanta como uma d'As Mais Belas Histórias, homem e natureza estão amalgamados - e a partida não deixa de ser uma espécie de condenação.

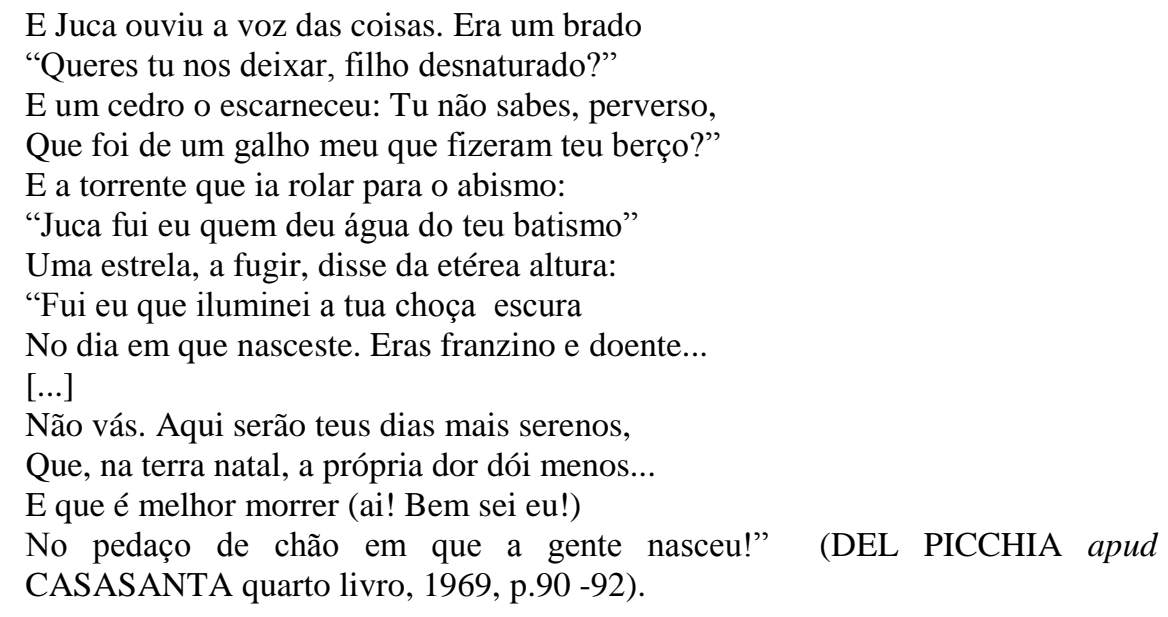

Destacamos que algumas das lições apresentadas eram consoantes ao processo histórico levado a cabo no período, em que a nação brasileira mais uma vez era convocada a superar o seu atraso via modernização capitalista. Daí a forte defesa dos valores do nacional desenvolvimentismo tão em voga. Também em função disso, as lições visavam não apenas explicar uma ordem social estável, mas, também, legitimá-la. Ao mesmo tempo em que se constituíam num conhecimento escolar, contribuíam para a elaboração das identidades, para difusão de normas, de condutas e de um sistema de valores constituintes da contraditória modernidade brasileira em curso.

\section{REFERÊNCIAS}

BATISTA, Antônio Augusto; GALVÃO, Ana Maria de Oliveira. Livros escolares de leitura no Brasil: elementos para uma história. Campinas: Mercado das Letras, 2009.

BITTENCOURT, Circe Maria Fernandes. Em foco: história, produção e memória do livro

\footnotetext{
${ }^{9}$ Paulo de Oliveira Leite Setubal (1893-1937). Poeta, romancista e cronista brasileiro. Fonte: $<$ http://enciclopedia.itaucultural.org.br/pessoa1881/paulo-setubal>).
} 
didático. Educação e Pesquisa, v.30 n.3. São Paulo, set./dez. 2004.

CASASANTA, Lúcia Monteiro. As mais belas histórias. Belo Horizonte: Editora do Brasil, 1969 (pré-livro, leitura intermediária, primeiro, segundo, terceiro e quarto livro).

CHARTIER, Roger. Aventura do livro: do leitor ao navegador. São Paulo: Unesp, 1998.

CHOPPIN, Alain.O manual escolar: uma falsa evidência histórica. História da Educação. v.13, n.27. jan. abr. 2009. p. 9 -75. Disponível em: <http://fae.ufpl.edu.br>. Acesso em: $<13$. dez. 2013>.

COSTA, A. M. da; SCHWARCZ, L.M. 1890-1914: - no tempo das certezas. São Paulo: Companhia das Letras, 2000.

CPDOC..GCg 1938.01.06: COLTED [Comissão do Livro Técnico e do Livro Didático], 1967, 44f. Disponível em:<http://www.fgv.br/cpdoc/acervo/arquivo-pessoal/GC/>. Acesso em: $\langle 05$ de out. de 2015>.

Arquivo Anísio Teixeira. A1piGarfinkel, E. 1951.08.10. Requisitos essenciais que devem preencher as Cartilhas. 11fl. Disponível em: <www.fgv/CPDOC/acervo/arquivopessoal/AT>. Acesso em: <20. Maio, 2015>.

CUNHA, Célio da. Educação e autoritarismo no Estado Novo. São Paulo: Cortez, 1981.

CUNHA, Marcus Vinícius da. O discurso educacional renovador no Brasil (1930-1960): um estudo sobre as relações ente escola e família, 1998. Tese de livre docência. Universidade Estadual Paulista.

CURY, Carlos Roberto Jamil. Alceu Amoroso Lima. Recife: Massananga, 2010.

DARTON, R. O beijo de Lamourette. Mídia, cultura e revolução. SP: Cia das Letras, 2010.

FARIA FILHO, L.M. de. Dos pardieiros aos palácios: cultura escolar e urbana em Belo Horizonte na Primeira República. Passo Fundo: UFP, 2000.

FREITAS, Marcos Cezar de; BICCAS, Maurilane de Souza. História social da educação no Brasil (1926 - 1996). São Paulo: Cortez, 2009. 
GATTI JÚNIOR, Décio. Estado e Editoras privadas no Brasil: o papel e o perfil das editoras de livros didáticos (1970- 1990). Cad. Cedes, Campinas, v.25, n. 67. p. 365 -377. set/dez. 2005. Disponível em: 〈http//www.cedes.unicamp.br>. Acesso em: <8. dez. 2015>.

HALLEWELL, Laurence. O livro no Brasil: sua história. São Paulo: EDUSP, 1985.

HERSCHMANN, Micael; PEREIRA, Carlos Alberto M. A invenção do Brasil moderno: medicina, educação e engenharia nos anos 20 e 30. Rio de Janeiro: Rocco, 1994.

INSTITUTO BRASILEIRO DE GEOGRAFIA E ESTATÍSTICA. (IBGE). Estatísticas do Século XX. Rio de Janeiro: Centro de Documentação e Disseminação de Informação, 2006. p. 301-344. Disponível em: 〈www.ibge.gov.br〉. Acesso em: <jul.2014>.

LE GOFF, Jacques. Introdução. In: . São Luís: biografia. 4. ed. Rio de Janeiro: Record, 2010, p. 19-32.

MACIEL, Francisca Izabel. Lúcia Casasanta e o método global de contos. Uma contribuição à história da alfabetização em Minas Gerais. 2001. Tese. Faculdade de Educação da Universidade Federal de Minas Gerais.

MOREIRA, Kênia Hilda; RODRIGUES, Eglem de Oliveira Passone. As pesquisas em História da Educação no Brasil com o livro didático. In: MOREIRA, Kênia Hilda; DÍAZ, José María Hernandez (Orgs.). História da Educação e livros didáticos. Campinas: Pontes Editores, 2017.

NUNES, Clarice; CARVALHO, Marta Maria Chagas de. Historiografia da Educação e fontes. In: GONDRA, José Gonçalves, et.al. (Org.). Pesquisa em História da Educação no Brasil. Rio de Janeiro: DP\&A, 2005.

PAIVA, Edil Vasconcelos; PAIXÃO, Léa Pinheiro. O Pabaee - A volta dos tempos de Francisco Campos e a oposição dos educadores católicos / Educação e Memória em Minas Gerais. Relatos de Pesquisa. 1995, v. 4, n.34. Disponível em: <www.publicações.inep.gov.br>. Acesso em: <8. jun. 2014>.

PALMER, Joy A. Grandes educadores: de Confúcio a Dewey. São Paulo: Contexto, 2005. SIRINELLI, Jean- François. Os intelectuais. In: RÈMOND, René. Por uma história política. Rio de Janeiro: UFRJ, 1996. p.249.

SOUZA, Ângela Leite de. Lúcia Casasanta, uma janela para a vida. Belo Horizonte: 
Imprensa Oficial, 1984.

SOUZA, Rosa Fátima de. História da organização do trabalho escolar e do currículo no século XX: [ensino primário e secundário no Brasil]. São Paulo: Cortez, 2008.

Recebido: $20 / 03 / 2017$

Aprovado: 22/04/2017 